Please do not remove this page

RMIT

UNIVERSITY

\title{
Conserving insect assemblages in urban landscapes: accounting for species-specific responses and imperfect detection
}

Mata, Luis; Goula, Marta; Hahs, Amy

https://researchrepository.rmit.edu.au/esploro/outputs/9921859759501341/filesAndLinks?institution=61RMIT_INST\&index=null

Mata, L., Goula, M., \& Hahs, A. (2014). Conserving insect assemblages in urban landscapes: accounting for species-specific responses and imperfect detection. Journal of Insect Conservation, 18(5), 885-894.

https://doi.org/10.1007/s10841-014-9696-7

Document Version: Accepted Manuscript

Published Version: https://doi.org/10.1007/s10841-014-9696-7

Repository homepage: https://researchrepository.rmit.edu.au

(C) 2014 Springer International Publishing Switzerland

Downloaded On 2023/04/26 19:45:30 +1000 
Thank you for downloading this document from the RMIT Research Repository.

The RMIT Research Repository is an open access database showcasing the research outputs of RMIT University researchers.

RMIT Research Repository: http://researchbank.rmit.edu.au/

\section{Citation:}

Mata, L, Goula, M and Hahs, A 2014, 'Conserving insect assemblages in urban landscapes: accounting for species-specific responses and imperfect detection', Journal of Insect Conservation, vol. 18 , no. 5 , pp. $885-894$.

See this record in the RMIT Research Repository at:

https://researchbank.rmit.edu.au/view/rmit:30237

Version: Accepted Manuscript

\section{Copyright Statement:}

(C) 2014 Springer International Publishing Switzerland

\section{Link to Published Version:}

https://researchbank.rmit.edu.au/view/rmit:30237 
Conserving insect assemblages in urban landscapes: accounting for species-specific responses and imperfect detection

Luis Mata ${ }^{1,2, *}$, Marta Goula ${ }^{1,3}$ and Amy K. Hahs ${ }^{4}$

${ }^{1}$ Departament de Biologia Animal, Universitat de Barcelona, Barcelona, 08028, Spain

${ }^{2}$ Interdisciplinary Conservation Science Research Group, School of Global, Urban \& Social Studies, RMIT University, Melbourne, Vic., 3001, Australia

${ }^{3}$ Institut de Recerca de la Biodiversitat, Universitat of Barcelona, Barcelona, 08028, Spain

${ }^{4}$ Australian Research Centre for Urban Ecology, Royal Botanic Gardens Melbourne c/o The School of Botany, The University of Melbourne, Parkville, Vic., 3010, Australia

* Corresponding author. E-Mail: luis.mata@ rmit.edu.au

Please cite as:

Mata L, Goula H, Hahs AK. 2014. Conserving insect assemblages in urban landscapes: accounting for species-specific responses and imperfect detection. Journal of Insect Conservation 18: 885-894.

Abstract

Understanding how global environmental change impacts insect biodiversity is central to the core principals of conservation biology. To preserve the ecosystem services provided by insects in cities, it is crucial to understand how insect species are influenced by the degree of urbanization of the surrounding landscape. Using a hierarchical occupancy-detection model, we estimated the effect of urbanization on heteropteran bug species richness and occupancy, an approach that concurrently accounts for speciesspecific responses and imperfect detection. We found that species richness decreased along a gradient of increasing urbanization. This trend corresponded well with species-specific trends, as approximately two thirds of all herbivores and predatory species experienced a strong mean negative response to urbanization. These results indicate that many species are potentially at risk of local extinction as cities grow and expand in the future. A second group of species, however, showed a weak mean negative response, indicating that they are ubiquitous urban species that thrive regardless of the surrounding degree of urban disturbance. Our research suggests that as cities develop, many of the species that are currently present will become less likely to occur, and therefore assemblages in the future are likely to become more simplified. In order to preserve or increase insect biological diversity in cities, it is critical to understand how individual species are influenced by urbanization. Our finding that insects display species-specific responses to urbanization has important repercussions for decision makers charged with preserving and improving urban biodiversity and the deliverance of ecosystem services in cities.

Keywords

Bayesian inference, Heteropteran bugs, Hierarchical models, Imperfect detection, Species-specific responses, Urban ecology

Introduction 
With over one million described living species, insects represent the world's most diversified eukaryotic taxa (Wilson 1992; Adler and Foottit 2009). The fundamental importance of insects for humankind, however, only comes to light when we take into account their functional role in food webs and life cycles, and their influence on agriculture, livestock and human health (Berenbaum 1996; Waldbauer 2003; Scudder 2009). All throughout the biosphere, the ecological functions performed by insects (eg, nutrient cycling, plant pollination, seed dispersal, soil structuring, population regulation and food provisioning) translate into a vast wealth of ecosystem services that are delivered to mankind (Losey and Vaughan 2006; Kremen and Chaplin-Kremer 2007; Straub et al. 2008). Notwithstanding, there is a general consensus that global environmental change is causing a biodiversity crisis in which a wide variety of species, including insects, are becoming extinct (Wilson 1992; Pimm et al. 1995; Levin 1999; Samways 2007; Stork 2010), and there is growing evidence that this loss of biological diversity modifies ecosystem function in a way that negatively impacts the deliverance of the ecosystem services most valued by society (Duffy 2009; Cardinale et al. 2012).

A principal human-induced factor contributing to loss of biological diversity, including that of insects, is land use change (Pimm and Raven 2000; Sala et al. 2000; Samways 2007). Arguably, the most pervasive driver of land use change is urbanization (Gaston 2010; Pickett et al. 2011; Seto et al. 2013). By destroying, reducing, fragmenting or otherwise transforming their habitats and resources, urbanization increases the vulnerability of many insect species to extinction (Samways 2007; New 2009). Not surprisingly, results from a wide array of studies indicate that moderate to high levels of urbanization correlate with low levels of insect species richness (McIntyre 2000; McKinney 2008; Luck and Smallbone 2010; Faeth et al. 2011). Ultimately, however, the response of insects to landscape-scale disturbances, including those generated by urbanization, are species-specific (McIntyre 2000; Hornung et al. 2007; McIntyre and Rango 2009; Magura et al. 2010; 2013; Shreeve and Dennis 2011; Tóthmérész et al. 2011; Horváth et al. 2012). Some species tend to be absent from highly urbanized areas, only showing high occupancy levels at low to intermediate levels of urbanization, whereas other species only occupy highly urbanized areas (McIntyre 2000; McKinney 2002; Hornung et al. 2007; Horváth et al. 2012). These latter species are generally adventive within the urban areas they inhabit (Wheeler and Hoebeke 2009), and their occupancy patterns are thought to have arisen through colonization processes that have repeatedly transferred them from one highly urbanized area into another (McKinney 2002; 2006). They can be therefore considered an important example of urbanization-driven biotic homogenization (McKinney 2010). The species-specific mechanisms driving the response of insects to urbanization gradients are poorly understood. Narrow habitat specialists may be especially prone to become extinct or locally extinct as urbanization completely or partially reduces the habitat they are restricted to (Dunn 2005). Likewise, host specialists dependent on plant species that are threatened by urbanization are likely to become co-extinct as a result of the extinction of their host (Moir et al. 2011). On the other hand, species that depend strongly on human resources to survive seem to thrive in highly urbanized areas (McIntyre 2000).

In order to preserve the deliverance of ecosystem services provided by insects in cities and towns around the world, it becomes imperative to understand how urbanization influences the species-specific response of insects and the species-specific factors that guarantee their persistence in urban areas. Previous studies 
on insect biodiversity in urban landscapes, however, have been generally focused at the community-level, hence relying almost exclusively on the analysis of species richness to infer the effects of urbanization (McKinney 2008 and references therein). Yet, as argued above, the effective conservation of a diverse assemblage of insect species in the urban context may depend on the management of landscape and habitat features that elicit a species-specific response (Fisher et al. 2004; Zipkin et al. 2009; Shreeve and Dennis 2011; Tóthmérész et al. 2011; Horváth et al. 2012; Magura et al. 2013). In the present study, we address this issue by simultaneously evaluating the effects of urbanization on both species richness and species-specific occurrence probabilities. Furthermore, most investigations of the effect of environmental gradients on insect species richness and/or occupancy have omitted the estimation of detection probabilities, although the importance of accounting for the imperfect detection of species is now widely recognized (MacKenzie et al. 2006; Royle and Dorazio 2008; Kéry 2011; Wintle et al. 2012; LahozManfort et al. 2013; Iknayan et al. 2014). We surveyed for adult heteropteran bugs living in herbaceous ruderal vegetation, and used a hierarchical occupancy-detection modelling approach to estimate the effect of urbanization on species richness and occupancy while accounting for insect species that are imperfectly detected.

Methods

Heteropteran bugs

With approximately 42,000 described species (Henry 2009), the Heteroptera Latreille, 1810 or true bugs constitute a monophyletic clade of hemimetabolous insects presenting a worldwide distribution (Schuh and Slater 1995; Weirauch and Schuh 2011). Most heteropteran bugs are strictly phytophagous, zoophagous or hematophagous (Schuh and Slater 1995; Schaefer and Panizzi 2000). Others display a wide range of mixed omnivorous behaviors ranging from phytozoophagy to zoophytophagy (Alomar and Widenmann 1999; Coll and Guershon 2002; Eubanks et al. 2003). Phytophagous species feed on roots, leaves, flowers, pollen, buds, seeds, fern fronds and fungi mycelia, while zoophagous species prey upon arthropods and even small vertebrates (Schuh and Slater 1995; Schaefer and Panizzi 2000). Predatory heteropteran bugs, through their capacity to regulate pest populations, are essential for ecosystem functioning and resilience against disturbance in human-dominated habitats and landscapes (Lattin 1999; 2000; Ambrose 2000; Braman 2000; Wheeler 2000b; Perdikis et al. 2011).

Study area

This study was conducted across the 30 municipalities that constitute the shire of El Maresme in Catalonia, Spain (north-east Iberian Peninsula). The shire is located between the Mediterranean Sea and the Sant Mateu, Corredor and Montnegre Massifs. It has a littoral Mediterranean climate: annual average precipitation oscillates between $550 \mathrm{~mm}$ at sea level and $800 \mathrm{~mm}$ in the mountains, and annual average temperatures vary from $8^{\circ} \mathrm{C}$ in the winter to $23^{\circ} \mathrm{C}$ in the summer (Servei Meteorològic de Catalunya 2010). The shire is home to 430,000 people and covers an area of approximately $400 \mathrm{~km}^{2}$, with the average municipality having an area of $13.2 \mathrm{~km}^{2}$ and a population of 14,325 inhabitants. These and other demographic data presented in this manuscript were provided by the Institut d'Estadística de Catalunya (2010), and additional data for each municipality are given in Table A (Online Resource 1).

Sampling design 
We collected heteropteran bugs living on herbaceous ruderal vegetation at two randomly selected independent sampling plots within a single site at each of the 30 municipalities. Species sampling took place between 18 March to 24 May 2011, coinciding with a known period of high adult heteropteran bug activity. The sites were defined here as the circular area of approximately $1.13 \mathrm{~km}^{2}(\mathrm{r}=750 \mathrm{~m})$ surrounding the historical centre point of each municipality's largest city or town. Sampling plots contained herbaceous ruderal vegetation that had not been mown, treated with pesticides or managed by any other means. Regarding their spatial distribution, plots were located at least: (1) $150 \mathrm{~m}$ away from the site's centre, (2) $150 \mathrm{~m}$ away from the boundary to the closest contiguous site, and (3) $500 \mathrm{~m}$ apart from each other. In seven sites, due to habitat unavailability, it was only possible to collect from one plot. At each plot, we used 100 sweeps of an entomological net to collect heteropteran bugs, which were posteriorly identified to species level. All plots were sampled twice during the survey's duration, thus two to four sampling replicates per municipality site were available for analyses. These spatial and temporal replicates were used to construct the species-specific detection histories that were fed into our occupancydetection model (as described below).

Urbanization data

The Institut Cartogràfic de Catalunya (2011) provided aerial photographs of each site, which we transformed in a GIS environment (ArcGIS version 10.1) into circular land-use maps ( $\mathrm{r}=750 \mathrm{~m}$ ). A radius of $750 \mathrm{~m}$ was used as this is the maximum radius that a city or town in El Maresme can have before it overlaps into the boundaries of another. We quantified each site's degree of urbanization using the Weeks' index of urbanization (Weeks et al. 2005). By quantifying the level of urban disturbance of each one of our sites we were effectively generating a continuous urbanization gradient (McDonnell and Pickett 1990; McDonnell and Hahs 2008) for the municipalities within the study area. To guarantee the repeatability and comparability of our study, we needed to construct this gradient using a standard broad measure of urbanization (McDonnell and Hahs 2008). We chose to use the Weeks' index of urbanization because it is a tested measure that efficiently integrates physical and social components of the urban landscape (Hahs and McDonnell 2006) using existing and easily available landscape and demographic data. The index, which is set to a 0 to 100 scale, combines land-use with census data to generate an urbanization gradient where higher values are associated with higher degrees of urbanization. With a mean value of 52, the index in our study area ranged from 27 to 79 . Additional data for each municipality are given in Table A (Online Resource 1).

Multi species site occupancy-detection model

To estimate the species richness of the whole heteropteran bug community, as well as that of its herbivorous and predatory guilds, and to quantify the effects of urbanization on the species-specific probabilities of occurrence, we used a multi-species site occupancy-detection model. This model is a powerful extension of the single-species hierarchical linear models used to estimate site occupancy rates of species that are imperfectly detected and/or of rare species with low occurrence probabilities (Dorazio and Royle 2005; Dorazio et al. 2006; Kéry and Royle 2008; Royle and Dorazio 2008; Zipkin et al. 2009; 2010; Iknayan et al. 2014). This modeling approach allows for the concurrent estimation of speciesspecific occurrence and detection probabilities, including the full range of their associated uncertainties. 
The model for occurrence was specified as:

$\mathrm{z}\left({ }_{i, j}\right) \sim \operatorname{Bernoulli}\left(\Psi_{i, j}\right)$

where $\Psi_{i, j}$ is the probability that species $i$ occurs at site $j$. The detection model, for which we have recorded data $\mathrm{x}(i, j, k)$ for species $i$ at site $j$ at the $k^{\text {th }}$ spatial or temporal replicate (ie, the species-specific detection history), was specified as:

$\mathbf{x}(i, j, k) \sim \operatorname{Bernoulli}\left(\Phi_{i, j, k} \cdot \mathrm{z}\left({ }_{i, j}\right)\right)$

where $\Phi_{i, j, k}$ is the detection probability of species $i$ at site $j$ at/during plot/period $k$. This satisfies the condition that the detection probability of a species will be zero when it is not present.

We incorporated the effect of urbanization into the linear predictor of our occupancy model on the logitprobability scale as follows:

$\operatorname{logit}\left(\Psi_{i, j}\right)=\mathrm{occ}_{i}+\mathrm{urb}_{i} \cdot \mathrm{iu}_{j}$

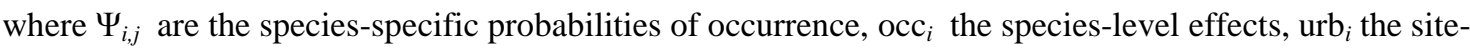
specific effect on occurrence, and $\mathrm{iu}_{j}$ are the values of the urbanization covariate (Weeks' index of urbanization). As no intermediate responses were found in the preliminary analyses, no quadratic terms were included in the final model. The covariate data was standardized so that its mean was zero and its standard deviation one. Since the survey was completed in less than 60 days, we confidently assumed that the heteropteran bug species pool remained constant, thus satisfying an important assumption of the model. We also assumed that the detection probability of species $i$ did not vary based on any measured covariate, thus it was determined by an unspecified species-level effect $\operatorname{det}_{i}$ as:

$\operatorname{logit}\left(\Phi_{i, j, k}\right)=\operatorname{det}_{i}$

Bayesian inference and model implementation

We considered all occurrence and detection parameters as random effects governed by hyperparameters, and estimated the model parameters and community summaries under a Bayesian mode of inference. We executed our Bayesian analysis following two key steps. First, we assigned to each model parameter a prior distribution. Because we lacked external knowledge of the system under study, we wanted our inferences to be based on the observed data alone. Thus all parameters and hyperparameters were given non-informative priors. Specifically, the means of the species-specific effects were given uniform priors that ranged between zero and one, while the means of the site-specific effects were given normal priors with mean zero and variance 1000. All standard deviations were given gamma priors with $\mathrm{r}$ and nu equal to 0.1. We then used the Markov Chain Monte Carlo (MCMC) simulation-based technique to draw samples from the posterior distribution of our parameters (McCarthy 2007; Kéry 2010). Here, we used the MCMC algorithms as implemented in the software OpenBUGS (Lunn et al. 2009), which was accessed through the R add-on package R2OpenBUGS (Sturtz et al. 2005). We used two chains of 30,000 iterations, discarded the first 3,000 iterations as burn-in, and thinned by two. Visual inspections of the MCMC chains plus values of the Gelman-Rubin statistic for all parameters $(\mathrm{R}-\mathrm{hat}<1.01)$ indicated acceptable convergence (Gelman and Hill 2007). The R/OpenBUGS model code and the data to re-run the analysis are given in Online Resource 2. 
Results

Our insect survey yielded 142 heteropteran bug species: 112 herbivores (79\%) and 30 predators $(21 \%)$ (see Table B in Online Resource 1). The most frequently collected herbivores were the oxycarenid Oxycarenus lavaterae, the lygaeid Nysius graminicola and the pentatomid shield bug Eurydema oleracea, together representing approximately one sixth of all detections. On the other hand, the most frequently collected predatory species were the anthocorid pirate bug Orius laevigatus, the dicyphinid mirid Macrolophus melanotoma and the geocorid Geocoris erythrocephalus, together accounting for approximately one twelfth of all detections.

Our model estimated that patches of ruderal herbaceous vegetation in El Maresme are occupied on average by 108 heteropteran bug species (95\% credible interval: 93, 121; Fig. 1a). Likewise, the model estimated the shire to be occupied on average by 85 herbivores (CI: 73, 96; Fig. 1b) and 23 predators (CI: 19, 26; Fig. 1c). Mean probability of occurrence was high (0.863) ranging from 0.712 to 0.970 (Fig. 2a), whereas detection was low (0.047) varying from 0.036 to 0.061 (Fig. 2b). As illustrated in Figure 3, municipality-level species richness estimates of the whole heteropteran community (Fig. 3a), as well as those of herbivores (Fig. 3b) and predators (Fig. 3c), showed a decreasing trend along the urbanization gradient. The mean community-level effect of urbanization on the occurrence probability of heteropteran bugs was negative (-1.154), and the posterior credible interval for this community hyperparameter contained only negative values (CI: $-2.013,-0.576)$.

Means, standard deviations and credible intervals for the 142 species-specific occurrence and detection probabilities are presented in Table B (Online Resource 1). Mean detection probabilities varied considerably among species $(0.018,0.517)$. The most frequently collected species, as described above, showed the highest probabilities of detection. Mean probabilities of occurrence varied among species from 0.614 to 0.979 .

We used the model's hyperparameters to predict heteropteran bug community-level probability of occurrence for 500 values within a reasonable range of the urbanization gradient. These predictions were then used to illustrate the negative relationships between urbanization and heteropteran bug occupancy (Fig. 4). In Fig. 4, besides representing the 95\% credible interval, we also illustrated the uncertainty associated with the mean effect by computing and plotting predicted relationships for 1000 random samples taken from the mean effect parameters's Markov Chain Monte Carlo draws. This is effectively equivalent to illustrating the $100 \%$ credible interval.

Likewise, we used the model's species-specific estimates to predict each species occurrence probability for 500 values of the urbanization gradient. This second set of predictions were used to illustrate the species-specific relationships between occupancy and urbanization (Fig. 5a). Overall, the mean speciesspecific effects were negative, ranging from -2.131 to -0.421 in herbivores, and from -2.015 to -0.083 in predators. The mean species-specific effects for each herbivorous and predatory taxa are given in Table $\mathrm{C}$ (Online Resource 1). Table $\mathrm{C}$ also provides 14 different quantile levels that can be combined to represent the $99 \%, 95 \%, 75 \%, 50 \%, 25 \%, 5 \%$ and $1 \%$ credible intervals (CIs) associated with the mean responses and to determine the widest CI not containing zero. Species associated with wide $99 \%, 95 \%$ and $75 \%$ CIs that do not overlap zero are those for which we can be confident that their probabilities of occurrence 
decreases along the urbanization gradient, whereas species in which the widest CI that does not contain zero is the $25 \%, 5 \%$ or $1 \% \mathrm{CI}$ are those we can be confident that their probability of occurrence is not negatively influenced by the gradient of urbanization. On the other hand, species in which the widest CI that does not contain zero is the $50 \% \mathrm{CI}$ are those for which we can expect their probability of occurrence to be equally independent of urbanization. The rhopalid Stictopleurus punctatonervosus was the herbivore that showed the strongest negative response to urbanization (mean $=-2.131 ; 99 \%$ credible interval: $6.180,-0.071$; Fig. $5 b)$. The strongest response from a predatory species was by the geocorid Geocoris erythrocephalus (mean $=-2.015$; 99\% CI: $-5.918,-0.342$; Fig. 5b). Other five herbivores (Ceraleptus gracilicornis, Dyroderes umbraculatus, Eurydema oleracea, Eurydema ornata and Neottiglossa bifida) showed strong responses in which the $95 \%$ CI did not overlap zero (Fig. 5b). A total of 70 herbivores and 20 predators showed a mean negative response in which the $75 \%$ CI did not contain zero. Among the herbivores, 32 species showed a mean negative response associated with a 50\% CI that did not cross zero, while 6 predatory species showed the same response. The rhopalid hyaline grass bug Liorhyssus hyalinus, the mirid plant bugs Lygus pratensis and Orthops kalmii, and the oxycarenid Oxycarenus lavaterae showed weak mean negative responses to the urbanization gradient in which the $25 \%$ credible interval was the widest interval of the posterior distribution that did not cross zero (Fig. 5c). Two mirid predatory species, the deraeocorinid Deraeocoris serenus and the dicyphinid Dicyphus maroccanus, also showed weak responses in which the $25 \% \mathrm{CI}$ did not overlap zero (Fig. 5c). The weakest mean response to the gradient of urbanization was shown by the anthocorid pirate bug Orius laevigatus (mean $=-0.083 ; 1 \%$ credible interval: $-0.022,-0.004$; Fig. 5c).

Discussion

The ongoing interest in understanding the effects of urbanization on biodiversity (Hahs et al. 2009; Luck and Smallbone 2010; Pickett et al. 2011; Elmqvist et al. 2013; McDonnell and Hahs 2013), including that of insects and other arthropods (McIntyre 2000; McIntyre and Rango 2009; Kotze et al. 2011) has led to a proliferation of studies assessing community and/or guild-level responses to urbanization (McKinney 2008 and reference therein, Niemelä and Kotze 2009; Sattler et al. 2010; Faeth et al. 2011). Here, we propose a new addition to this research area by presenting an approach that simultaneously assesses heteropteran bug community, guild and species-specific responses to a gradient of urbanization. Our study was further strengthened by a comprehensive and well replicated assessment of the heteropteran bug diversity in the region, which allowed us to generate the encounter histories necessary for our occupancy-detection modelling approach to account for the imperfect detection of species. Models that fail to account for imperfect detection may yield less accurate estimates of species richness and biased inferences of the effects of covariates (Kéry 2011; Wintle et al. 2012; Lahoz-Manfort et al. 2013; Iknayan et al. 2014). Our study was also unique in that it investigated insect responses along the urban-to-rural gradient of more than a single urban area. In fact, we investigated how heteropteran bug species assemblages varied across a gradient of different sized cities, using a broad measure of urbanization that ensured the comparability and repeatability of the study across other urban regions.

Our results suggest that heteropteran bug species richness decreases along a gradient of increasing urbanization (Fig. 3a). This result supports the findings of McKinney (2008), which reviewed 57 studies on different insect and arachnid taxa and reported that over $70 \%$ of the studies showed species richness to 
peak at low levels of urbanization. Our results further suggest that the species richness of both herbivorous and predatory heteropteran bugs also decreases along the urbanization gradient (Fig. 3b-c). These guild level results partially contradict those presented by Sattler et al. (2010), which working with at least 25 different insect and arachnid taxonomic groups found that, while the species richness of herbivores showed no response, the species richness of predators, including reduviid, nabid and anthocorid heteropteran bug species, had a negative response to urbanization. Likewise, Niemelä and Kotze (2009), reviewing the response of carabid beetles to urban-to-rural gradients across eight cities, reported that, with a few exceptions, the species richness of this predatory group decreased along the gradients of increasing urbanization. Overall, these findings may contribute to emphasize the trophic downgrading presently affecting global ecosystems (Estes et al. 2011), and add to the growing body of evidence supporting the hypothesis that the higher trophic levels are most likely to be affected by urbanization (Fischer et al. 2012).

The mean community-level effect of urbanization on the occurrence probability of heteropteran bugs was negative, and the posterior credible interval for this community hyperparameter contained only negative values. This suggests that most species in the community are less likely to occur as the degree of urbanization increases along the gradient (Fig. 4). This trend is reflected in the trends of individual species along the urbanization gradients, as approximately $68 \%$ of all herbivorous and $70 \%$ of all predatory species experienced a strong mean negative response associated with wide credible intervals that not overlapped zero (Table C and Fig. 5a-b). These results therefore highlight that many of the heteropteran bugs utilizing the herbaceous ruderal vegetation in the study area tend to drop out as the degree of urbanization increases, and are therefore potentially at risk of local extinction as these cities grow and expand in the future. A second group of species showed a weak mean negative response to the degree of urban disturbance in which the associated credible intervals that did not cross zero were very narrow (Table $\mathrm{C}$ and Fig. 5c), indicating that they are ubiquitous urban species that are equally likely to occur in all cities and town regardless of their degree of urbanization. Included among these species were the polyphagous pests L. hyalinus, O. lavaterae and L. pratensis (Schaefer and Kotulski 2000; Sweet 2000; Wheeler 2000a), which indicates that heteropteran bug species potentially responsible for significant plant damage are likely to persist as urban areas expand. Interestingly, also included in this latter group was the well-known generalist pest control agent $O$. laevigatus (Lattin 1999; 2000), as well as other understudied predatory species such as $D$. serenus and D. maroccanus, highlighting that at least some natural enemies seem to thrive in patches of herbaceous ruderal vegetation regardless of the surrounding degree of urbanization.

In this study we have provided quantitative evidence for relationships between urbanization and insect species richness and occupancy. The nature of these relationships, however, remains correlative rather than causative, an issue that has been previously highlighted regarding the urbanization gradient approach in ecological and conservation investigations (Catterall 2009). Nevertheless, as a first approximation to understand the causative mechanisms driving patterns of species richness and occupancy in urban regions, we believe our research may provide foundational knowledge essential for future studies. For instance, potential mechanistic explanations for the occupancy patterns reported in this study may be better understood by researching the vegetation structural complexity of herbaceous ruderal urban 
ecosystems. This approach may further advance our understanding of the role unmanaged herbaceous vegetation may play within urban areas in the conservation of insect biodiversity. Likewise, fine-scaled mechanisms driving the occupancy patterns of predatory species in urban ecosystems may be elucidated by investigating more closely how their occurrence is dependent on the availability of their prey, and how this availability in turn relates to the size and density of the surrounding urban area, as well as with its connectivity with the larger non-urban landscape. We therefore anticipate that further studies may benefit from characterizing the urban context through more specific measures of urbanization (McDonnell and Hahs 2008; 2013; Hahs et al. 2009; Kotze et al. 2011).

Our research suggests that as cities grow and develop, most of the insect species that are currently present will become less likely to occur, and therefore the insect assemblages in the future are likely to become more simplified and increasingly composed of cosmopolitan species. In order to preserve and/or increase insect biological diversity in urban ecosystems, and their associated ecosystem services, we believe it is expedient to understand how individual species are influenced by the process of urbanization, especially since the availability of a rich insect fauna is important for other terrestrial animal groups such as birds, mammals and reptiles. Our finding that insect's response to urbanization is distinctly species-specific has important repercussions for decision makers charged with preserving and improving urban biological diversity and the ecosystem services provided by insects in urban landscapes.

Acknowledgements

The authors wish to thank Helena Casellas, Josep Solà and Araceli Torró for their assistant during field work, landscape characterization, insect sorting and heteropteran bug identification. We also thank Gurutzeta Guillera-Arroita and Jose Lahoz-Monfort for their help with the statistical model. Field work was partially supported by the 'Emerging Research Groups Funding Program' (Faculty of Biology, University of Barcelona). LM wishes to acknowledge the support of funding from the Agència de Gestió d'Ajuts Universitaris i de Recerca (AGAUR), the Australian Government's national Environmental Research Program (NERP) and the Australian Research Council Centre of Excellence for Environmental Decisions (CEED). AKH would like to acknowledge financial support from the Baker Foundation. The manuscript greatly benefited from the comments from three anonymous reviewers.

References

Adler PH, Foottit RG (2009) Introduction. In: Foottit R, Adler P (eds) Insect biodiversity - Science and society. Wiley-Blackwell, Chichester, pp 1-6

Alomar O, Widenmann R (eds) (1999) Zoophytophagous Heteroptera: implications for life history and integrated pest management. Entomological Society of America, Maryland

Ambrose DP (2000) Assassin bugs (Reduviidae excluding Triatominae). In: Schaefer CW, Panizzi AR (eds) Heteroptera of economic importance. CRC Press, Boca Raton, pp 695-712

Berenbaum M (1996) Bugs in the system: Insects and their impact on human affairs. Helix Books, Cambridge

Braman SK (2000) Damsel bugs (Nabidae). In: Schaefer CW, Panizzi AR (eds) Heteroptera of economic importance. CRC Press, Boca Raton, pp 639-656 
Cardinale B, Duffy J, Gonzalez A, Hooper D, Perrings C, Venail P, Narwani A, Mace G, Tilman D, Wardle D, Kinzig A, Daily G, Loreau M, Grace J, Larigauderie A, Srivastava D, Naem S (2012)

Biodiversity loss and its impact on humanity. Nature 486:59-67

Catterall CP (2009) Responses of faunal assemblages to urbanization: global research paradigms and an avian case study. In: McDonnell M, Hahs AK, Breuste J (eds) Ecology of cities and towns: a comparative approach. Cambridge University Press, Cambridge, pp 129-155

Coll M, Guershon M (2002) Omnivory in terrestrial arthropods: mixing plant and prey diets. Annu Rev Entomol 47:267-297

Dorazio R, Royle J (2005) Estimating size and composition of biological communities by modeling the occurrence of species. J Am Statist Assoc 100:389-398

Dorazio R, Royle J, Söderström B, Glimskär A (2006) Estimating species richness and accumulation by modeling species occurrence and detectability. Ecology 87:842-854

Duffy J (2009) Why biodiversity is important to the functioning of real-world ecosystems. Front Ecol Environ 7:437-444

Dunn RR (2005) Modern insect extinctions, the neglected majority. Conserv Biol 19:1030-1036

Elmqvist T, Fragkias M, Goodness J, Güneralp B, Marcotullio PJ, McDonald RI, Parnell S, Schewenius M, Sendstad M, Seto KC, Wilkinson C, Alberti M, Folke C, Frantzeskaki N, Haase D, Katti M, Nagendra H, Niemelä J, Pickett STA, Redman CL, Tidball K (2013) Stewardship of the biosphere in the urban era. In: Elmqvist T, Fragkias M, Goodness J, Güneralp B, Marcotullio PJ, McDonald RI, Parnell S, Schewenius M, Sendstad M, Seto KC, Wilkinson C (eds) Urbanization, Biodiversity and Ecosystem Services: Challenges and Opportunities. Springer, pp 719-746

Estes J, Terborgh J, Brashares J, Power M, Berger J, Bond W, Carpenter S, Essington T, Holt R, Jackson, Marquis R, Oksanen L, Oksanen T, Paine R, Pikitch E, Ripple W, Sandin S, Scheffer M, Schoener T, Shurin J, Sinclair A, Soulé M, Virtanen R, Wardle D (2011) Trophic downgrading of planet earth. Science 333:301-306

Eubanks M, Styrsky J, Denno R (2003) The evolution of omnivory in heteropteran insects. Ecology $84: 2549-2556$

Faeth SH, Bang C, Saari S (2011) Urban biodiversity: patterns and mechanisms. Ann NY Acad Sci 1223:69-81

Fischer J, Cleeton S, Lyons T, Miller J (2012) Urbanization and the predation paradox: the role of trophic dynamics in structuring vertebrate communities. Bioscience 69:809-818

Fischer J, Lindenmayer DB, Cowling A (2004) The challenge of managing multiple species at multiple scales: reptiles in an Australian grazing landscape. J Appl Ecol 41:32-44

Gaston K (2010) Urbanization. In: Gaston K (ed) Urban ecology. Cambridge University Press, Cambridge, pp 10-34 
Gelman A, Hill J (2007) Data analysis using regression and multilevel/hierarchical models. Cambridge University Press, Cambridge

Hahs AK, McDonnell M (2006) Selecting independent measures to quantify Melbourne's urban-rural gradient. Landsc Urban Plan 78:435-448

Hahs AK, McDonnell M, Breuste J (2009) A comparative ecology of cities and towns: synthesis of opportunities and limitations. In: McDonnell M, Hahs AK, Breuste J (eds) Ecology of cities and towns: a comparative approach. Cambridge University Press, Cambridge, pp 574-596

Henry T (2009) Biodiversity of Heteroptera. In: Foottit R, Adler P (eds) Insect biodiversity - Science and society. Wiley-Blackwell, Chichester, pp 223-263

Hornung E, Tóthmérész B, Magura T, Vilisics F (2007) Changes of isopod assemblages along an urbansuburban-rural gradient in Hungary. Eur J Soil Bio 43:158-165

Horváth R, Magura T, Tóthmérész B (2012) Ignoring ecological demands masks the real effect of urbanization: a case study of ground-dwelling spiders along a rural-urban gradient in a lowland forest in Hungary. Ecol Res 27:1069-1077

Iknayan KJ, Tingley MW, Furnas BJ, Beissinger SR (2014) Detecting diversity: emerging methods to estimate species diversity. Trends Ecol Evol 29:97-106

Institut Cartogràfic de Catalunya (2011) http://www.icc.es. Accessed 25 February 2014 Institut d'Estadística de Catalunya (2010) http://idescat.cat. Accessed 25 February 2014

Kéry M (2010) Introduction to WinBUGS for ecologists. A Bayesian approach to regression, ANOVA, mixed models and related analyses. Academic Press, Burlington

Kéry M (2011) Towards the modelling of true species distributions. J Biogeogr 38:617-618

Kéry M, Royle J (2008) Hierarchical Bayes estimation of species richness and occupancy in spatially replicated surveys. J Appl Ecol 45:589-598

Kotze J, Venn S, Niemelä J, Spence J (2011) Effects of urbanization on the ecology and evolution of arthropods. In: Niemelä J (ed) Urban Ecology. Patterns, processes and applications. Oxford University Press, New York, pp 159-166

Kremen C, Chaplin-Kremer R (2007) Insects as providers of ecosystem services: crop pollination and pest control. In: Stewart A, New T, Lewis O (eds) Insect Conservation Biology: proceedings of the Royal Entomological Society’s 23rd Symposium. CABI Publishing, Wallingford, pp 349-382

Lahoz-Monfort JJ, Guillera-Arroita G, Wintle BA (2013) Imperfect detection impacts the performance of species distribution models. Global Ecol Biogeogr. doi:10.1111/geb.12138

Lattin JD (1999) Bionomics of the Anthocoridae. Annu Rev Entomol 44:207-231

Lattin JD (2000) Minute pirate bugs (Anthocoridae). In: Schaefer CW, Panizzi AR (eds) Heteroptera of economic importance. CRC Press, Boca Raton, pp 607-637

Levin S (1999) Fragile dominion. Perseus Books, Reading 
Losey J, Vaughan M (2006) The economic value of ecological services provided by insects. Bioscience 56:311-323

Luck G, Smallbone L (2010) Species diversity and urbanization: patterns, drivers and implications. In: Gaston K (ed) Urban ecology. Cambridge University Press, Cambridge, pp 88-119

Lunn D, Spiegelhalter D, Thomas A, Best N (2009) The BUGS project: evolution, critique and future directions. Stat Med 28:3049-3067

MacKenzie D, Nichols J, Royle A, Pollock K, Hines J, Bailey L (2006) Occupancy estimation and modeling: inferring patterns and dynamics of species occurrence. Elsevier, San Diego

Magura T, Lövei GL, Tóthmérész B (2010) Does urbanization decrease diversity in ground beetle (Carabidae) assemblages? Global Ecol Biogeogr 19:16-26

Magura T, Nagy D, Tóthmérész B (2013) Rove beetles respond heterogeneously to urbanization. J Insect Conserv 17:715-724

McCarthy M (2007) Bayesian methods for ecology. Cambridge University Press, Cambridge

McDonnell M, Hahs AK (2008) The use of gradient analysis studies in advancing our understanding of the ecology of urbanizing landscapes: current status and future directions. Landsc Ecol 23:1143-1155

McDonnell M, Hahs AK (2013) The future of urban biodiversity research: Moving beyond the 'lowhanging fruit'. Urban Ecosyst 16:397-409

McDonnell M, Pickett S (1990) Ecosystem structure and function along urban-rural gradients: an unexploited opportunity for ecology. Ecology 71:1232-1237

McIntyre N (2000) Ecology of urban arthropods: a review and a call to action. Ann Entomol Soc Am 98:825-835

McIntyre N, Rango J (2009) Arthropods in urban ecosystems: community patterns as functions of anthropogenic land use. In: McDonnell M, Hahs AK, Breuste J (eds) Ecology of cities and towns: a comparative approach. Cambridge University Press, Cambridge, pp 233-242

McKinney M (2002) Urbanization, biodiversity, and conservation. Bioscience 52:883-889

McKinney M (2006) Urbanization as a major cause of biotic homogenization. Biol Conserv 127:247-260

McKinney M (2008) Effects of urbanization on species richness: a review of plants and animals. Urban Ecol 11:161-176

McKinney M (2010) Urban futures. In: Gaston K (ed) Urban ecology. Cambridge University Press, Cambridge, pp 287-308

Moir ML, Vesk PA, Brennan KE, Keith DA, McCarthy MA, Hughes L (2011) Identifying and managing threatened invertebrates through assessments of coextinction risk. Conserv Biol 25:787-796

New TR (2009) Insect species conservation. Cambridge University Press, Cambridge

Niemelä J, Kotze J (2009) Carabid beetle assemblages along urban to rural gradients: a review. Landsc Urban Plan 92:65-71 
Perdikis D, Fantinou A, Lykouressis D (2011) Enhancing pest control in annual crops by conservation of predatory Heteroptera. Biol Control 59:13-21

Pickett S, Cadenasso M, Grove J, Boone C, Groffman P, Irwin E, Kaushal S, Marshall V, McGrath B, Nilon C, Pouyat R, Szlavecz K, Troy A, Warren P (2011) Urban ecological systems: scientific foundations and a decade of progress. J Environ Manage 92:331-362

Pimm SL, Raven P (2000) Biodiversity—extinction by numbers. Nature 403:843-845

Pimm SL, Russell G, Gittleman J, Brooks T (1995) The future of biodiversity. Nature 269:347-350

Royle J, Dorazio R (2008) Hierarchical modeling and inference in ecology. The analysis of data from populations, metapopulations and communities. Academic Press, London

Sala OE, Chapin FS, Armesto JJ, Berlow E, Bloomfield J, Dirzo R, Huber-Sanwald E, Huenneke LF, Jackson RB, Kinzig A, Leemans R, Lodge DM, Mooney HA, Oesterheld M, Poff NL, Sykes MT, Walker BH, Walker M, Wall DH (2000) Global biodiversity scenarios for the year 2100. Science 287:1770-1774 Samways MJ (2007) Insect conservation: a synthetic management approach. Annu Rev Entomol 52:465487

Sattler T, Duelli P, Obrist M, Arlettaz R, Moretti M (2010) Response of arthropod species richness and functional groups to urban habitat structure and management. Landsc Ecol 25:941-954

Schaefer CW, Kotulski J (2000) Scentless plant bugs (Rhopalidae). In: Schaefer CW, Panizzi AR (eds) Heteroptera of economic importance. CRC Press, Boca Raton, pp 309-319

Schaefer CW, Panizzi AR (2000) Economic importance of Heteroptera: a general view. In: Schaefer CW, Panizzi AR (eds) Heteroptera of economic importance. CRC Press, Boca Raton, pp 3-8

Schuh R, Slater J (1995) True bugs of the world (Hemiptera: Heteroptera). Classification and natural history. Cornell University Press, Ithaca

Scudder G (2009) The importance of insects. In: Foottit R, Adler P (eds) Insect biodiversity - Science and society. Wiley-Blackwell, Chichester, pp 7-32

Servei Meteorològic de Catalunya (2010) http://www.meteo.cat. Accessed 25 Febraury 2014

Seto KC, Parnell S, Elmqvist T (2013) A global outlook on urbanization. In: Elmqvist T, Fragkias M, Goodness J, Güneralp B, Marcotullio PJ, McDonald RI, Parnell S, Schewenius M, Sendstad M, Seto KC, Wilkinson C (eds) Urbanization, Biodiversity and Ecosystem Services: Challenges and Opportunities. Springer, pp 1-12

Shreeve TG, Dennis RLH (2011) Landscape scale conservation: resources, behavior, the matrix and opportunities. J Insect Conserv 15:179-188

Stork N (2010) Re-assessing current extinction rates. Biodivers Conserv 19:357-371

Straub C, Finke D, Snyder W (2008) Are the conservation of natural enemy biodiversity and biological control compatible goals? Biol Control 45:225-237

Sturtz S, Ligges U, Gelman A (2005) R2WinBUGS: a package for running WinBUGS from R. J Stat Softw 12:1-16 
Sweet, MH (2000) Seed and chinch bugs (Lygaeoidea). In: Schaefer CW, Panizzi AR (eds) Heteroptera of economic importance. CRC Press, Boca Raton, pp 143-264

Tóthmérész B, Máthé I, Balázs E, Magura T (2011) Responses of carabid beetles to urbanization in Transylvania (Romania). Landsc Urban Plan 101:330-337

Waldbauer G (2003) What good are bugs? Harvard University Press, Cambridge

Weeks J, Larson D, Fugate D (2005) Patterns of urban land use as assessed by satellite imagery: an application to Cairo, Egypt. In: Entwisle B, Rindfuss, Stern P (eds) Population, land use, and environment: research directions. The National Academies Press, San Diego, pp 265-286

Weirauch C, Schuh R (2011) Systematics and evolution of Heteroptera: 25 years of progress. Annu Rev Entomol 56:487-510

Wheeler AG (2000a) Plant bugs (Miridae) as plant pest. In: Schaefer CW, Panizzi AR (eds) Heteroptera of economic importance. CRC Press, Boca Raton, pp 37-83

Wheeler AG (2000b) Predacious plant bugs (Miridae). In: Schaefer CW, Panizzi AR (eds) Heteroptera of economic importance. CRC Press, Boca Raton, pp 657-693

Wheeler AG, Hoebeke ER (2009) Adventive (non-native) insects: importance to science and society. In: Foottit R, Adler P (eds) Insect biodiversity - Science and society. Wiley-Blackwell, Chichester, pp 475521

Wilson E (1992) The diversity of life. Norton and Company, New York

Wintle BA, Walshe T, Parris K, McCarthy MA (2012) Designing occupancy surveys and interpreting non-detection when observations are imperfect. Divers Distrib 18:417-424

Zipkin E, DeWan A, Royle A (2009) Impacts of forest fragmentation on species richness: a hierarchical approach to community modelling. J Appl Ecol 46:815-822

Zipkin E, Royle A, Dawson D, Bates S (2010) Multi-species occurrence models to evaluate the effects of conservation and management actions. Biol Conserv 143:479-484 


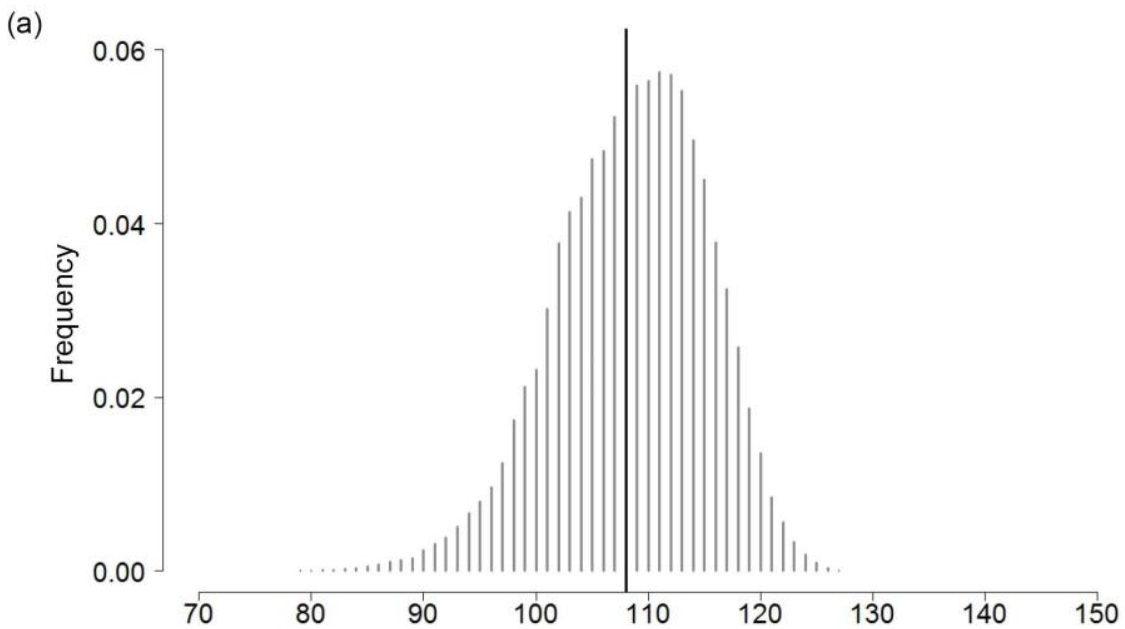

(b)

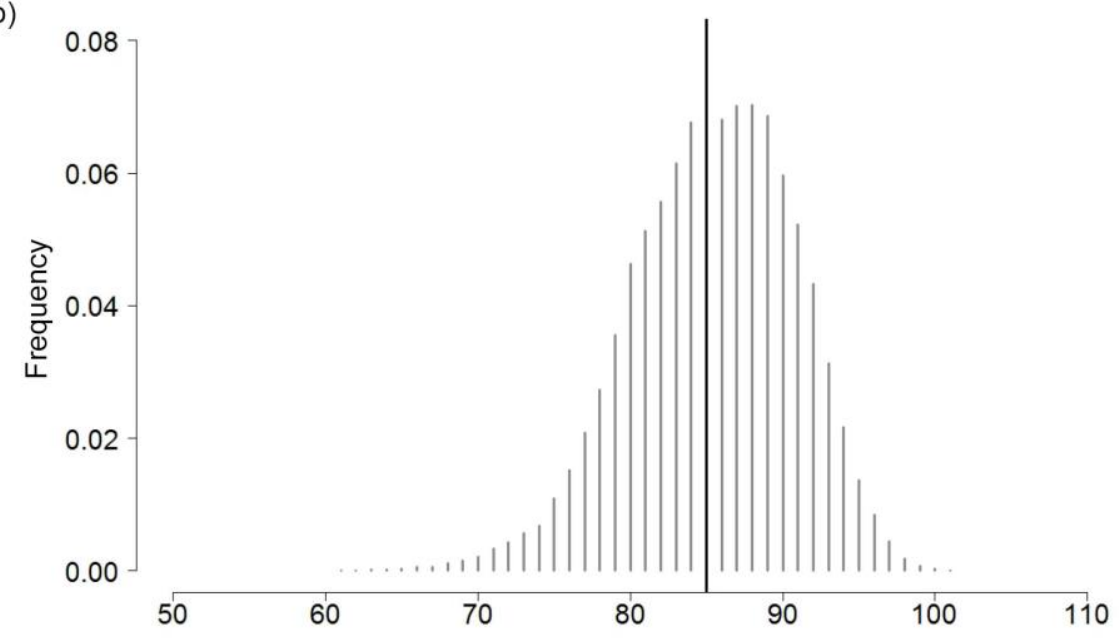

(c)

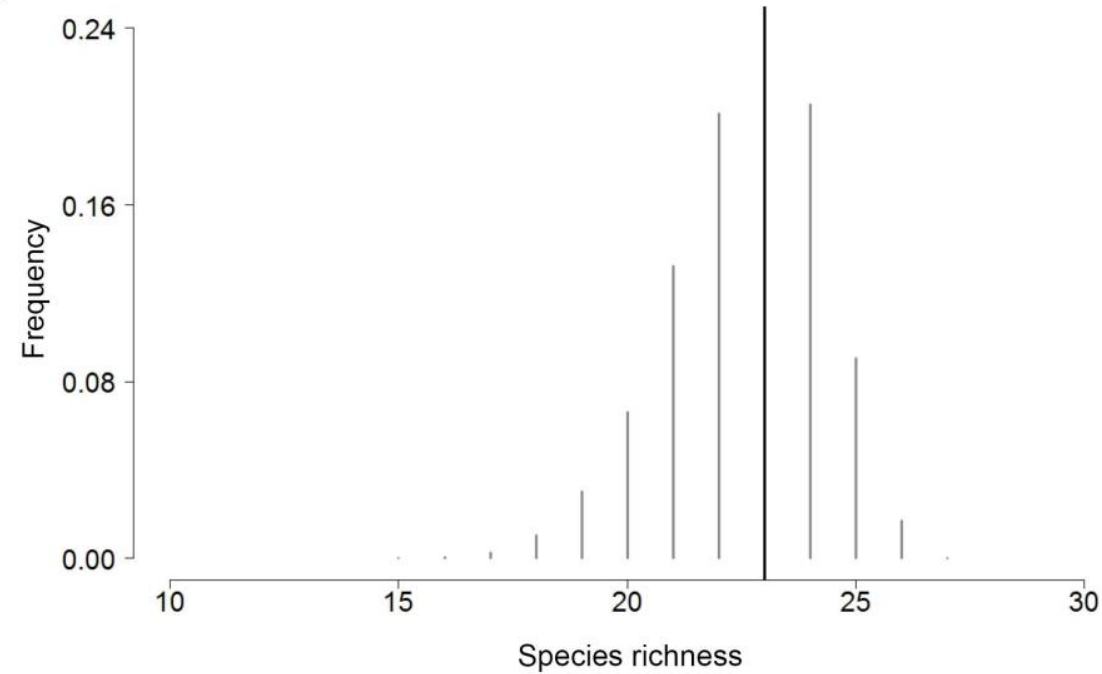


Fig. 1 Posterior distributions of heteropteran bug mean species richness for El Maresme shire for the (a) whole community, (b) herbivorous guild, and (c) predatory guild. The black bar indicates the mean response

(a)

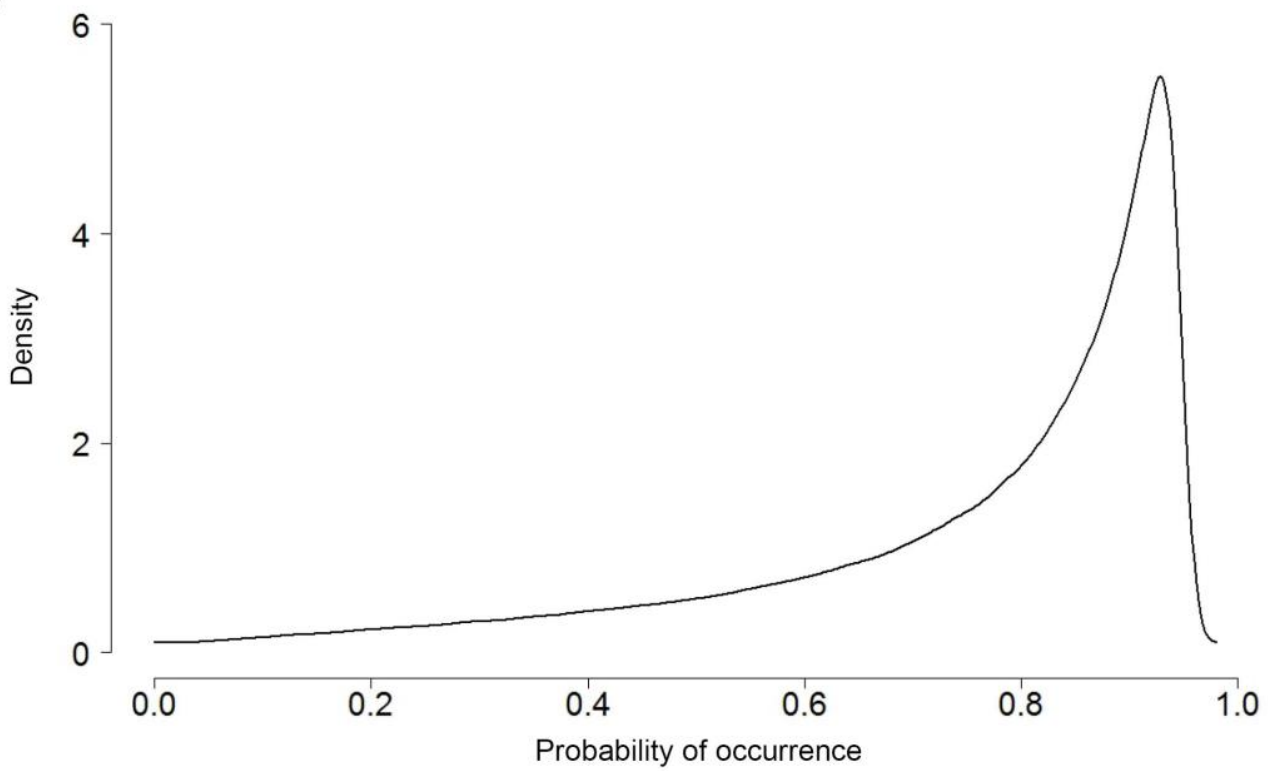

(b)

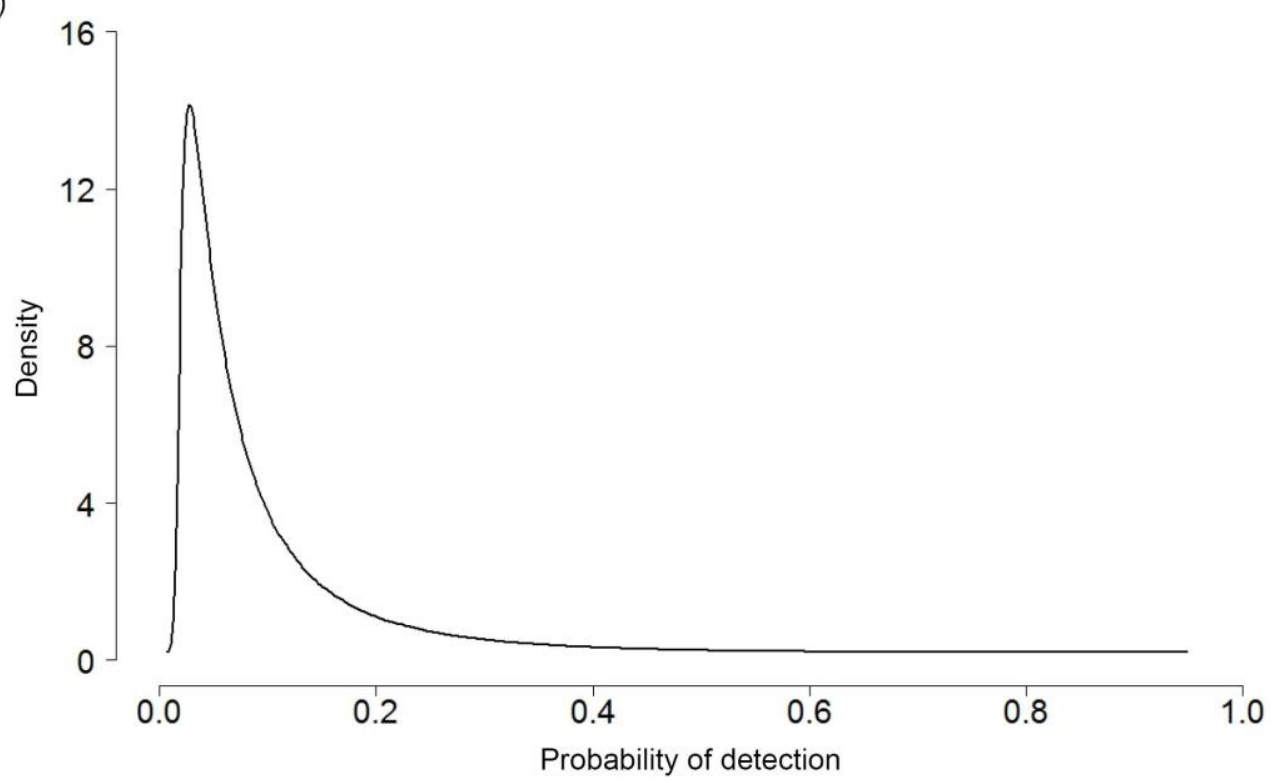


Fig. 2 Distributions of probabilities of occurrence (a) and detection (b) of heteropteran bugs in El Maresme shire based on model estimates

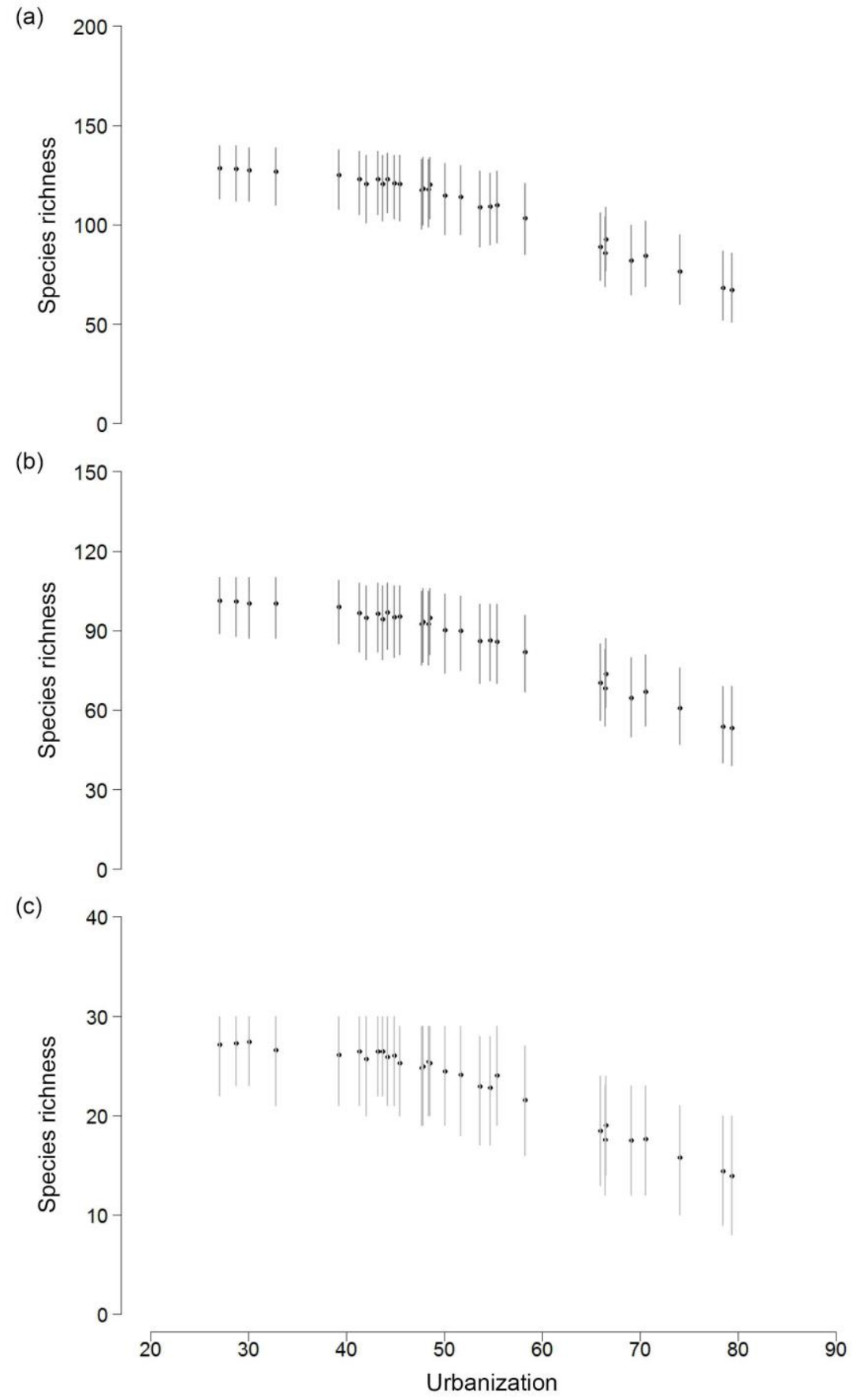


Fig. 3 Relationships between species richness and urbanization for the (a) whole community, (b) herbivorous guild, and (c) predatory guild. The solid black dots indicate means and the grey vertical bars the $95 \%$ credible intervals

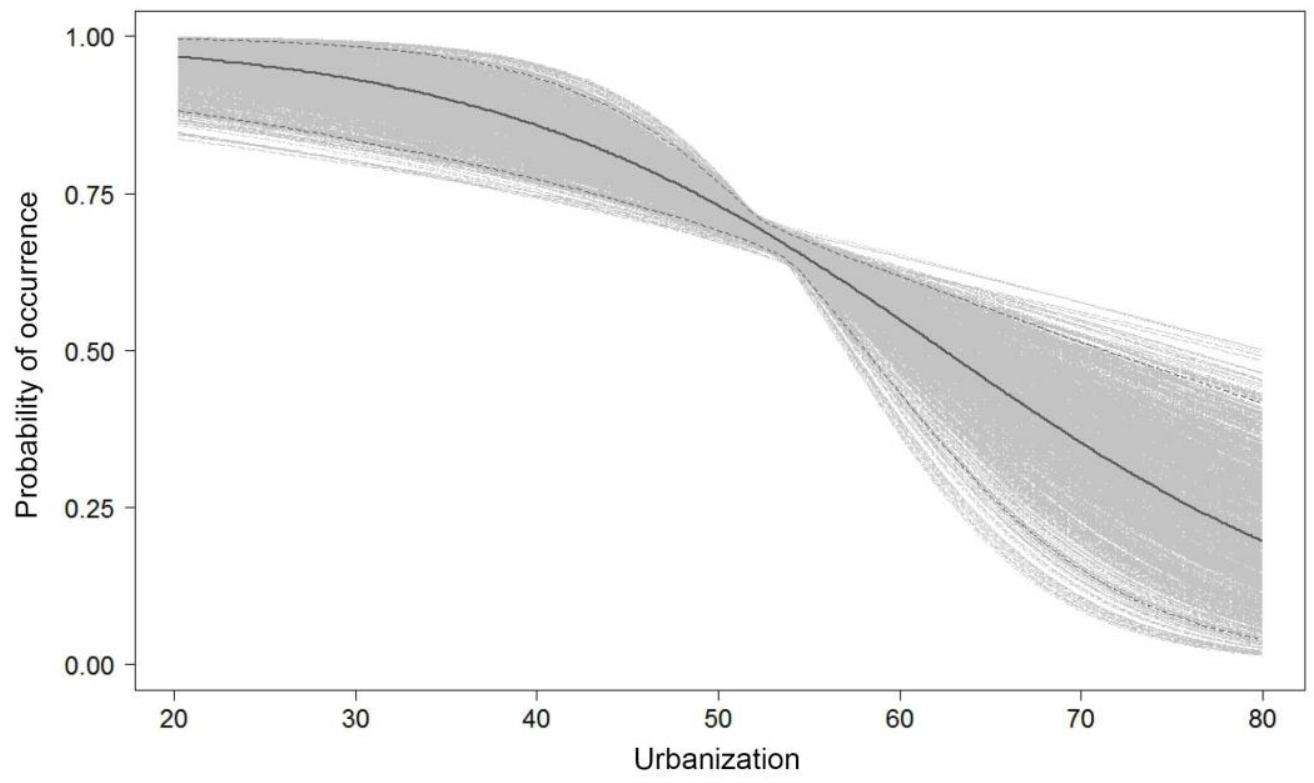


Fig. 4 Predicted relationships between heteropteran bug community-level occupancy and urbanization. The black solid line represents the mean, while the black dashed lines represent the $95 \%$ credible interval. The grey lines represent the full range of uncertainty associated with the mean response
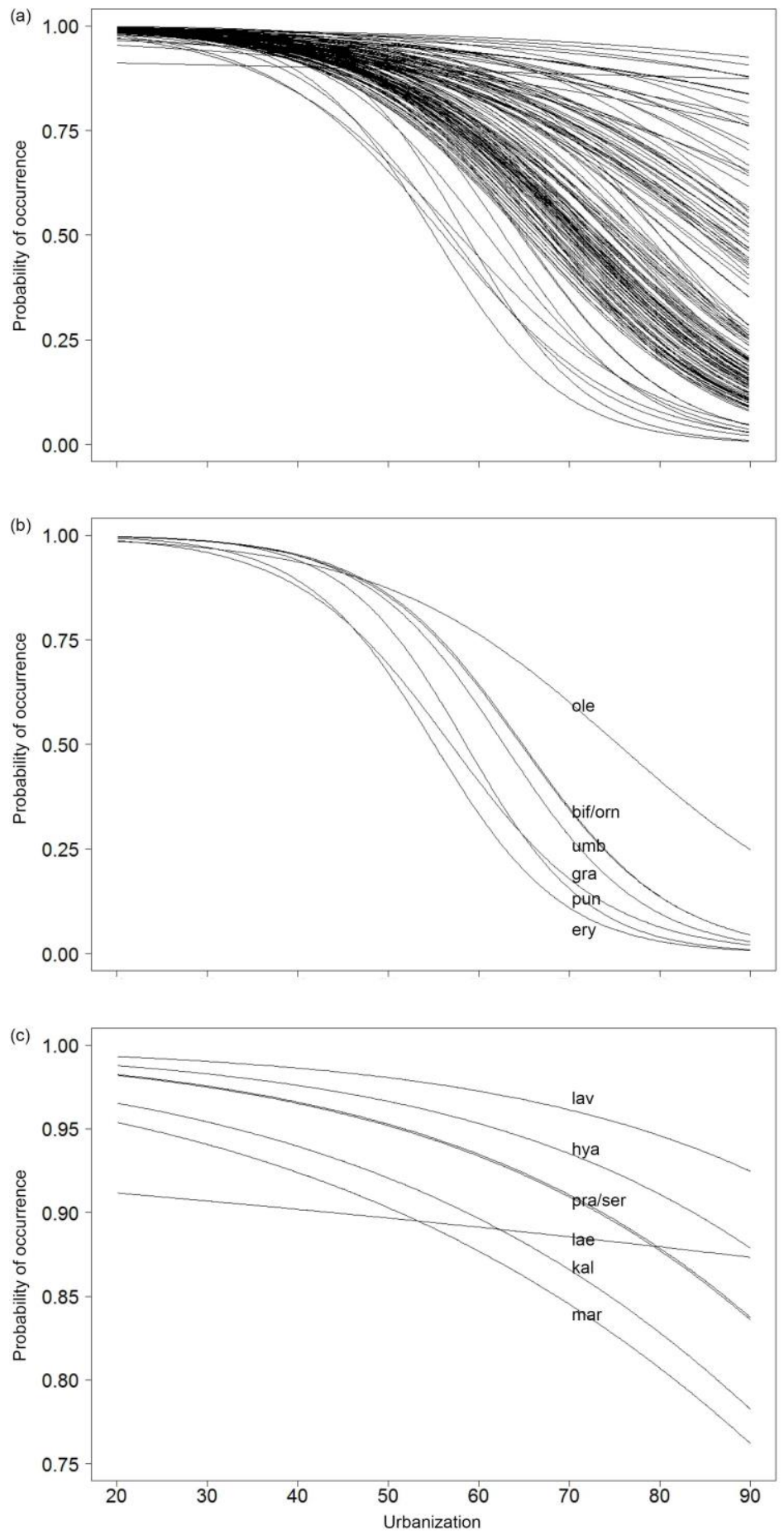
Fig. 5 Predicted relationships between mean heteropteran bug species-specific probabilities of occurrence and urbanization for the (a) whole community, (b) species showing the strongest mean negative response and the widest credible intervals not overlapping zero, and (c) species showing the weakest mean negative response and the narrowest credible intervals not overlapping zero. The posterior summaries for each one of the 142 species-specific responses are given in Table C (Online Resource 2). Species legend: bif: Neottiglossa bifida, ery: Geocoris erythrocephalus, gra: Ceraleptus gracilicornis, hya: Liorhyssus hyalinus, kal: Orthops kalmii, lae: Orius laevigatus, lav: Oxycarenus lavaterae, mar: Dicyphus maroccanus, orn: Eurydema ornata, pra: Lygus pratensis, pun: Stictopleurus punctatonervosus, ser: Deraeocoris serenus, and umb: Dyroderes umbraculatus

Electronic supplementary material

Online Resource 1:

Table A Municipality data

Table B Species-specific summaries for occurrence and detection

Table C Species-specific summaries for effects of urbanization

Online Resource 2:

R/OpenBUGS model code and data 